\title{
Time Varying Correlations between Stock and Bond Returns: Empirical Evidence from Russia
}

\author{
Kashif Saleem \\ Lappeenranta School of Business, \\ Lappeenranta Univeristy of Technology, Finland \\ E-mail:kashif.saleem@lut.fi
}

Received: September 23, 2011 Accepted: November 21, 2011 Published: December 1, 2011

doi:10.5296/ajfa.v3i1.989 URL: http://dx.doi.org/10.5296/ajfa.v3i1.989

\begin{abstract}
The purpose of this study is to look at the relationship between the stock and the bond market of Russia. By using multivariate conditional volatility models, such as, Bollerslev (1990) CCC model, Engle (2002) the DCC model, we first examine whether the correlations between two classes of assets are constant or time varying. Secondly, to investigate the asymmetries in conditional variances, covariances, and correlations, an asymmetric version of the DCC model proposed by Cappiello et al. (2006) is adopted. The empirical results do not support the assumption of constant conditional correlation and there was clear evidence of time varying correlations between the Russian stocks and bond market. Both asset markets exhibit positive asymmetries.
\end{abstract}

Keywords: DCC-GARCH, Time varying correlations, Russia, Asymmetric, Emerging market

JEL classification: C32, G15 


\section{Introduction}

Since the seminal work by Markowitz $(1952,1959)$ clearly addresses the importance of stock-bond correlation in constructing the optimal portfolio, examination of the co-movements between the stock and bond markets has been one of the most fundamental questions to portfolio managers, risk analysts and financial researchers, among others, in recent past. However, the question is still open and there is no general consensus among financial researchers on the dynamics of the stock-bond correlation and how it might perform in the future. For instance, Keim and Stambaugh (1986), Campbell and Ammer (1993), and Kwan (1996) empirically support the theoretical argument of positive correlation among stocks and bonds. On the other hand Gulko (2002), Connolly et al. (2005) and Baur and Lucey (2009) support the phenomenon of "flight to quality" and "flight from quality" which reflects a negative correlation between the two assets, and additionally, Alexander et al. (2000) found mixed sign correlations.

Moreover, prior literature is divided into two distinct opinions regarding the co-movement of two assets; for example, Shiller and Beltratti (1992) and Campbell and Ammer (1993) are among those who implicitly assume that stock-bond correlation is time invariant. In contrast, Scruggs and Glabadanidis (2003) strongly reject models that impose a constant correlation restriction on the covariance matrix between stock and bond returns. Furthermore, Siegel (1998), Gulko (2002), Cappiello, Engle and Sheppard (2006), Ilmanen (2003), Connolly et al. (2005), Jones and Wilson (2004) and Li (2002) are among those who have shown that the correlation between stock and bond returns exhibits considerable time variation, whereas Barsky (1989) is of the view that stock and bond co-movements are state dependent.

Furthermore, despite its importance, this phenomenon has been severely ignored in the context of emerging markets, regardless of their high returns and favourable diversification opportunities. There is no doubt that futures, options and different kinds of derivative products have acquired an ever increasing importance in today's modern finance. However, stocks and bonds are still the primary securities traded on stock exchanges and the major component of any optimal portfolio, especially in emerging markets. Since the risk-return characteristics of stocks and bonds are very different, stock-bond correlation plays an important role in asset allocation, portfolio management and risk management. It is therefore a natural question to ask whether there is a relationship between the returns on stocks and bonds, considering the main objective of a portfolio manger, i.e., to construct a portfolio that has the largest expected return with a minimum risk. Moreover, the above-mentioned contradictory empirics motivate us to explore this issue further and especially in the context of emerging markets.

There are several techniques to model the correlations between the returns on the stock and bond markets, but the conventional method relies on a simple regression analysis or takes an unconditional correlation based on a specific sample period, such as rolling window correlation estimation. However, the past two and a half decades have witnessed a high development in time series analysis, especially after the seminal works of Engle (1982) and Bollerslev (1986). Multivariate GARCH models have been extensively applied to investigate 
the co-movements between different asset markets. However, studies dealing with the interdependence across the stock and bond markets are scarce, particularly within the context of emerging markets. In the early days, Bollerslev et al. (1988), among others, proposed a VECH model to inspect the correlation between the bond and stock market in the USA. Later, the BEKK model of Engle and Kroner (1995) became popular to test the linkage between different markets and it has also been applied to examine the relationship between the stock and bond markets (see, e.g., Scruggs and Glabadanidis, 2003). Similarly, the Constant Correlation Coefficient model of Bollerslev (1990) has been applied to investigate the linkage between the stock and bond markets (see, e.g., Abid et al., 2003)

The most recent addition in the class of Multivariate GARCH models is the Dynamic Conditional Correlation (DCC) model of Engle (2002). This model has a clear advantage over previous models as it avoids computational complexities, estimates large conditional variance-covariance matrices and also circumvents the convergence problems. Moreover, the DCC model perfectly overcomes the heteroskedasticity problem since the residuals of the returns are standardized by the conditional standard deviation based on the GARCH $(1,1)$ process. However, it does not account for the asymmetries in conditional variances, covariances, and correlations, but thanks to Cappiello et al. (2006) this oversight was corrected because they recently proposed an Asymmetric version of the Dynamic Conditional Correlation (ADCC) model to deal with the asymmetries in the conditional variances, covariances, and correlations of two assets.

Over the past few years the Russian equity and fixed income markets have shown a tremendous attraction to both domestic and international investors due to their rapid growth and corrective measures taken by the Russian policy makers. Although the Russian market is considered risky (see, e.g., Saleem and Vaihekoski, 2008), it is also a fact that today Russia is a mainstream market for international investors who are interested to diversify their portfolios geographically. Therefore, the Russian equity market is worth investigation. In this study the attempt is to model the correlations between the returns on the stock and bond markets of Russia. Firstly, we question whether the co-movement between the two asset classes is constant over time by utilizing Bollerslev's (1990) Constant Conditional Correlation model. Further, to analyze the dynamics of the time varying conditional correlations between the two assets we use the DCC-GARCH $(1,1)$ model proposed by Engle (2002). Finally, to investigate the asymmetries in conditional variances, covariances, and correlations, we adopt an asymmetric version of the Dynamic Conditional Correlation (ADCC) model proposed by Cappiello et al. (2006). The empirical results do not support the assumption of constant conditional correlation and there was clear evidence of time varying correlations between the Russian stocks and bond market. Moreover, both asset markets exhibit positive asymmetries.

In general, the results offer a better understanding of the dynamics of the correlations between stocks and bonds in an emerging market setting which is obviously very valuable for portfolio managers, international investors, risk analysts and financial researchers as well as for its policy implications.

The structure of the paper is as follows. The next section describes the model specifications 
used to study the correlations among Russian stock and bond markets. Section 3 presents the data in this study. Section 4 shows the empirical results, and Section 5 provides conclusions.

\section{Model Specification}

Various approaches have been suggested for the modeling of the correlations between two assets. The simplest one is the rolling window correlation. However, due to its fixed window and equal weights given to all the sample points in a data set, it may ignore the structural changes with different degrees of volatility in a time series. Bollerslev et al. (1988), among others, proposed a model in the early days to check the conditional covariances between bills, bonds, and stocks; however, the model was not able to assure the positive definiteness of the conditional variance matrix. Moreover, this approach does not allow the cross equation conditional variances and covariances to affect each other due to oversimplifying restrictions. Many of these problems are circumvented by the Constant Conditional Correlation (CCC) model proposed by Bollerslev (1990). However, the assumption of constant correlation is perhaps relatively uncertain and may not hold always. For example, prior research has documented high correlations among financial markets during crisis periods (see, e.g., Chesnay and Jondeau, 2001).

Following Bollerslev (1990), Engle and Sheppard (2001) and Engle (2002), this empirical specification starts with the assumption that stock market returns from the $k$ series are multivariate and normally distributed with zero mean and conditional variance-covariance matrix $H t$. Hence, this multivariate DCC-GARCH model can be presented as follows:

$$
r_{t}=\mu_{t}+\varepsilon_{t}
$$

with $\varepsilon_{t} \mid \Omega_{t-1} \rightarrow N\left(0, H_{t}\right)$ where, $\boldsymbol{r}_{\boldsymbol{t}}$ is the $(k \times 1)$ vector of the returns; $\boldsymbol{\varepsilon} t$ is a $(k \times 1)$ vector of zero mean return innovations conditional on the information, $\Omega_{t-1}$, available at time $t$ - 1 and for the bi-variate case, the conditional variance-covariance matrix $\left(\boldsymbol{H}_{t}\right)$ in the DCC model can be expressed as:

$$
H_{t}=D_{t} R_{t} D_{t}
$$

Here $\boldsymbol{D}$ represents a $(k \times k)$ diagonal matrix of the conditional volatility of the returns on each asset in the sample and $\boldsymbol{R}_{\boldsymbol{t}}$ is the $(k \times k)$ conditional correlation matrix. Basically, the DCC-GARCH model estimates conditional volatilities and correlations in two steps. In the first step the mean equation of each asset in the sample, nested in a univariate GARCH model of its conditional variance is estimated. Hence, we can define $\boldsymbol{D}_{\boldsymbol{t}}$ as follows:

$$
D_{t}=\operatorname{diag}\left(h_{i i t}^{1 / 2} \ldots \ldots . . h_{k k t}^{1 / 2}\right) \text {, }
$$

where $\boldsymbol{h}_{i i t}$, conditional variance of each asset is assumed to follow a univariate $\operatorname{GARCH}(\mathrm{p}, \mathrm{q})$ process given by the following expression: 


$$
h_{i, t+1}=\omega_{i}+\sum_{p=1}^{p i} \alpha_{i, p} \varepsilon_{i, t+1-p}^{2}+\sum_{q=1}^{Q i} \beta_{i, q} h_{i, t-p}
$$

However, to insure non-negativity and stationarity, some restrictions, such as, $\alpha_{i, p}>0, \beta_{i, q}>$ 0 and $\sum_{p=1}^{p i} \alpha_{i, p}+\sum_{q=1}^{q i} \beta_{i, q}<1$ should be imposed. These univariate variance estimates are then used to standardize the zero mean return innovations for each asset.

In the second step, the standardized zero mean return innovations are assumed to follow a multivariate GARCH $(\mathrm{m}, \mathrm{n})$ process to illustrate the development of the time varying correlation matrix, $\boldsymbol{R}$, which can be described as follows:

$$
R_{t}=\left(\operatorname{diag} Q_{t}\right)^{-1 / 2} Q_{t}\left(\operatorname{diag} Q_{t}\right)^{-1 / 2},
$$

where $Q_{t}=(1-\alpha-\beta) \bar{Q}+\alpha \delta_{t-1} \delta_{t-1}^{\prime}+\beta Q_{t-1}$ refers to a $(k \times k)$ symmetric positive definite matrix and $\delta_{i t}=\varepsilon_{i t} / \sqrt{h_{i t}}, \bar{Q}$ is the $(k \times k)$ unconditional variance matrix of $\delta_{i t}$, and $\alpha$ and $\beta$ are non-negative scalar parameters satisfying $\alpha+\beta<1$. Finally, the conditional correlation coefficient $\rho_{i j}$ between two assets $i$ and $j$ is then expressed by the following equation:

$$
\rho_{i j}=\frac{(1-\alpha-\beta) \overline{q_{i j}}+\alpha \mu_{i, t-1} \mu_{j, t-1}+\beta q_{i j, t-1}}{\left\langle(1-\alpha-\beta) \overline{q_{i i}}+\alpha \mu_{i, t-1}^{2}+\beta q_{i i, t-1}\right\rangle^{1 / 2}\left\langle(1-\alpha-\beta) \overline{q_{j j}}+\alpha \mu_{j, t-1}^{2}+\beta q_{j j, t-1}\right\rangle^{1 / 2}},
$$

As per Engle and Sheppard (2001) and Engle (2002) this model can be estimated with the quasi-maximum likelihood method (QMLE) given below:

$$
L=-\frac{1}{2} \sum_{t-1}^{T}\left(n \log (2 \pi)+2 \log \left|D_{t}\right|+\log \left|R_{t}\right|+\delta^{\prime}{ }_{t} R_{t}^{-1} \delta_{t}\right),
$$

Since $\delta_{t}=\varepsilon_{t} / \sqrt{h_{t}}=D_{t}^{-1} \varepsilon_{t}$ the log-likelihood function can be rewritten as follows:

$$
L=-\frac{1}{2} \sum_{t-1}^{T}\left(n \log (2 \pi)+2 \log \left|D_{t} R_{t} D_{t}\right|+\varepsilon_{t}^{\prime} D_{t}^{-1} R_{t}^{-1} D_{t}^{-1} \varepsilon_{t}\right),
$$

As the DCC model does not allow for asymmetries and asset specific news impact parameter, the modified model of Cappiello et al. (2006) for incorporating the asymmetrical effect and asset specific news impact can be written as: 


$$
Q_{t}=\left(\bar{Q}-A^{\prime} \bar{Q} A-B^{\prime} \bar{Q} B-G^{\prime} \bar{N} G\right)+A^{\prime} \varepsilon_{t-1} \varepsilon_{t-1}^{\prime} A+B^{\prime} Q_{t-1} B+G^{\prime} n_{t-1} n_{t-1}^{\prime} G
$$

where $\mathrm{A}, \mathrm{B}$ and $\mathrm{G}$ are diagonal parameter matrixes, $n_{t}=I\left[\varepsilon_{t}<0\right] o \varepsilon_{t}$ (with $o$ indicating Hadamard product), $\bar{N}=E\left[n_{t} n_{t}^{\prime}\right]$. For $\bar{Q}$ and $\bar{N}$ expectations are infeasible and are replaced with sample analogues, $T^{-1} \sum_{t-1}^{T} \varepsilon_{t} \varepsilon_{t}^{\prime}$ and $T^{-1} \sum_{t-1}^{T} n_{t} n_{t}^{\prime}$, respectively.

\section{Data and Descriptive Statistics}

Daily total return indices for the Russian market calculated by DataStream are used as proxy for Russian stocks ${ }^{1}$. The JP Morgan EMBI Russia index (proxy for Russian bond market) is used to model the key factors influencing movements in the Russian bond market. The dataset starts from July 1994 and ends at December 2007, yielding 3522 observations for each series. The beginning of this data set is due to the availability of the total return index for Russia, and the use of daily data (over a five-day period) in this study is to get meaningful statistical generalizations and to obtain a better picture of the movements of stock-bond returns.

Daily returns are constructed as the first difference of logarithmic prices multiplied by 100 . Table 1 presents a wide range of descriptive statistics for both of the series under investigation. As a first step, stationarity in the time series is checked by applying the Augmented Dickey Fuller (ADF) test. The results (see Table 1) allow us to reject the null hypothesis that returns have a unit root in favor of the alternate hypothesis of stationarity (even at 1\% MacKinnon critical value). The development of both asset indices is shown in Figure 1. This clearly exhibits non-stationarity in both return indices.

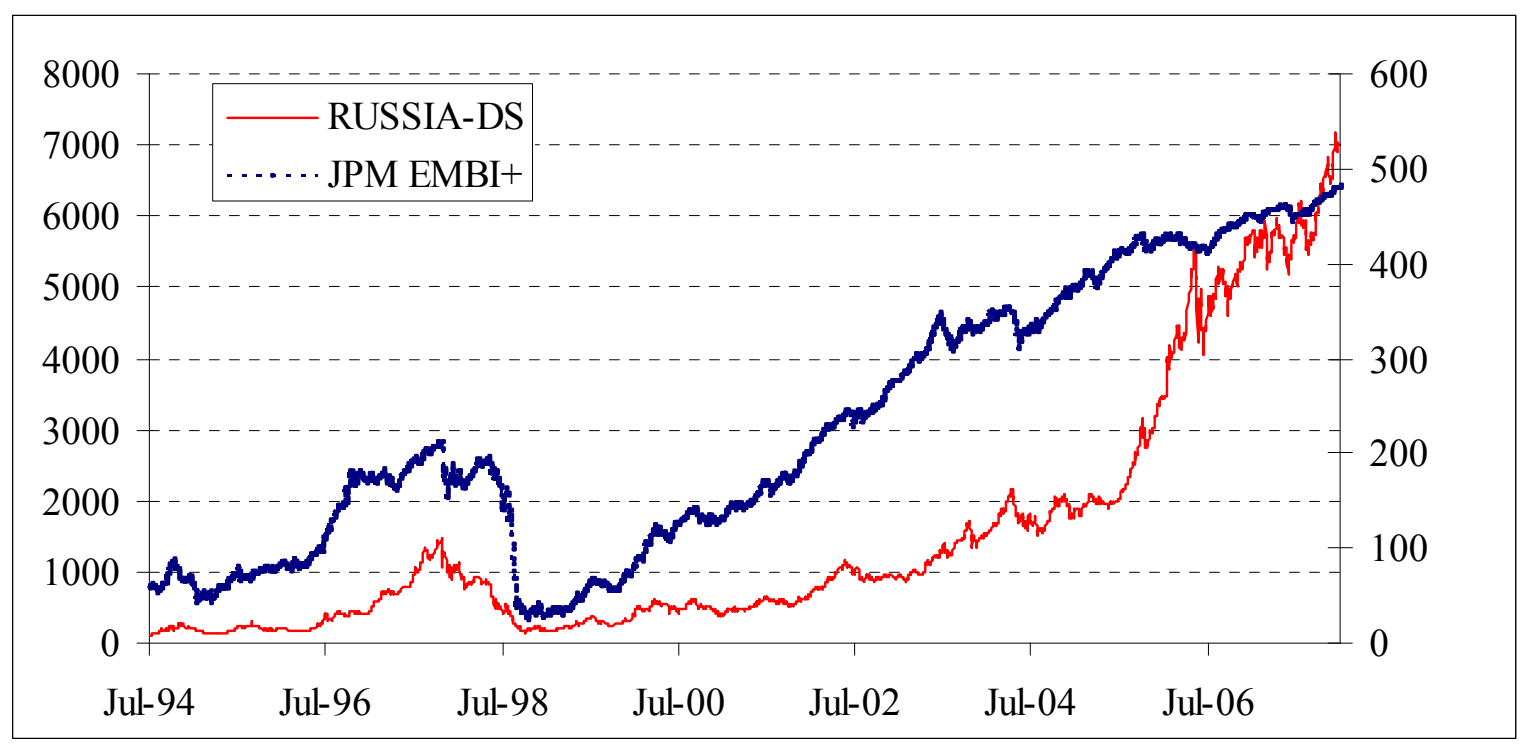

Figure 1. Development of Russian equity market indices (left axis) and the JPM EMBI Russia index (right axis) from 1994 to 2007.

1 Note that the total return index series is an index series and not a return series. 
The first two moments of the data, i.e., mean and standard deviation, are multiplied by $240^{2}$ and the square root of 240 to show them in annual terms. As can be anticipated, stock market indices have higher returns as compared to the bond market, however, the high returns are clearly associated with high risks (standard deviations).

Both the return series are, without exception, highly leptokurtic and exhibit strong skewness. This suggests the presence of asymmetry in the return series of both stocks and bonds. To check the null hypothesis of normal distribution the Jarque-Bera test statistic was calculated which rejected the null of the normality in both cases.

Table 1. Summary of descriptive statistics for the Russian stock and bond market.

\begin{tabular}{|llllllllll|}
\hline & Mean & Std. dev. & Skewness Kurtosis & JB & ADF & LB $_{(24)}$ & LB $_{(24)}^{2}$ LM \\
\hline Stock & 28.686 & 40.865 & 0.358 & 26.199 & $<0.001^{*}$ & $-57.386^{*}$ & $52.831^{*}$ & $593.04^{*}$ & $118.304^{*}$ \\
Bond & 14.331 & 29.794 & -1.582 & 42.109 & $0.001^{*}$ & $-30.017^{*}$ & $228.490^{*}$ & $3381.6^{*}$ & $226.439^{*}$ \\
\hline
\end{tabular}

* indicates significance at 5\% level.

Descriptive statistics are provided for Russian stock and bond market returns. Stocks market returns are proxied by logarithmic returns on Datastream daily total return index for Russia. Bond market returns are proxied by logarithmic returns on JP. Morgan EMBI Russia daily index. Sample period is from July 1994 to December 2007. Mean and standard deviations are annualized by multiplying them by 240 and the square root of 240. JB stands for Jarque-Bera test on normality of the returns. P-value is reported. ADF stands for Augmented Dickey Fuller test to check the stationarity in the time series. LB stands for Ljung-Box test statistic.

Since the GARCH process to model the variance in the asset returns was used, the presence of the ARCH effect was also tested for. Table 1 reports values for the Ljung-Box test statistic on the squared returns (24 lags) together with the ARCH LM statistic (five lags) on each returns series. The results show evidence of an autocorrelation pattern in both residuals and their squares, which suggests that GARCH parameterization might be appropriate for the conditional variance processes.

\section{Empirical Results}

\subsection{Constant Conditional Correlation estimates}

Following Bollerslev (1990), this investigation started with the assumption of constant conditional correlation in a multivariate $\mathrm{GARCH}$ setting where variance-covariance terms are time varying. The $\mathrm{CCC}$ model $^{3}$ seemed to be the best starting point as it avoids computational complexities and assures the positive definiteness of the conditional variance-covariance matrix as well as the conditional correlation matrix. Table 2 presents the

\footnotetext{
${ }^{2}$ We chose 5 working days length in a week, so 20 days in one month and 240 working days per year.

3 The estimation is conducted using a modified RATS routines originally available at www.estima.com
} 
results. Parameter $\mu$ corresponds to the mean equation, whereas $\omega, \alpha$ and $\beta$ represent the conditional variance of both the stock and bond returns which are modeled by a separate univariate $\operatorname{GARCH}(1,1)$ model with no drift parameters. Finally $\rho$ characterizes the correlation between the two assets.

All parameters are found highly significant and positive; the significance of mean equation parameter $\mu$ shows the dependence of both stock and bond returns on their lag returns, and variance equation parameters $\alpha$ and $\beta$ support this modeling technique, i.e. the multivariate GARCH analysis, by revealing the presence of conditional hetroskedasticity in the time series. The estimated constant conditional correlation between the two assets is 0.213 . Since it is positive it can be argued that both stock and bond markets are exposed to common macroeconomic conditions. The estimated coefficient of CCC reflects the lower co-movements between the two assets which is consistent with prior literature (see, e.g., Keim and Stambaugh, 1986; Campbell and Ammer, 1993) and also provides a better opportunity for optimal portfolio selection. Since the CCC model assumes that the conditional correlations are constant over time, rolling conditional correlations were estimated with a window size set to six months to check the validity of this assumption.

Table 2. Bond-stock bivariate CCC-GARCH $(1,1)$ model

\begin{tabular}{llllll}
\hline & $\boldsymbol{\mu}$ & $\omega$ & $\alpha$ & $\beta$ & $\rho$ \\
\hline \multirow{2}{*}{ Stock } & $0.156^{*}$ & $0.080^{*}$ & $0.021^{*}$ & $0.978^{*}$ & \\
& $(0.031)$ & $(0.000)$ & $(0.001)$ & $(0.001)$ & $0.213^{*}$ \\
& & & & & \\
Bond & $0.061^{*}$ & $0.006^{*}$ & $0.080^{*}$ & $0.919^{*}$ & \\
& $(0.007)$ & $(0.000)$ & $(0.005)$ & $(0.005)$ & $(0.013)$ \\
\hline
\end{tabular}

Results are reported from a bivariate constant conditional correlation $\operatorname{GARCH}(1,1)$ process; conducted by using daily returns on bond and stock market indices for Russia from July 1994 to December 2007. In the Table, $\mu$ represents the constant from the mean equation whereas $\omega$, $\alpha$ and $\beta$ are the parameters of bivariate GARCH processes. The parameter $\rho$ stands for the correlation between two assets. Standard errors are in ( ). * indicates the significance at $5 \%$ level.

The developments of the stock-bond return correlations in the Russian equity market indices and the JPM EMBI Russia index are plotted in Figure 2. The gray line represents a six-month rolling window correlation, whereas the brown line stands for conditional correlation produced by the DCC model. Several interesting features emerge from this figure. Except for the period of 1995-96 the correlations in both indices are positive. From the first quarter of 1996 the correlations were constantly increasing until the collapse of the Russian financial market in August 1998. Moreover, Figure 3 indicates that the stock-bond correlation fluctuated substantially during the period of 1999 and 2003 and then it became rather stable. This may pose challenges for asset allocation and risk management procedures. It is apparent 
that the relation between stock and bond returns has been rather unstable over time, which is clear evidence against the constant correlation hypothesis.

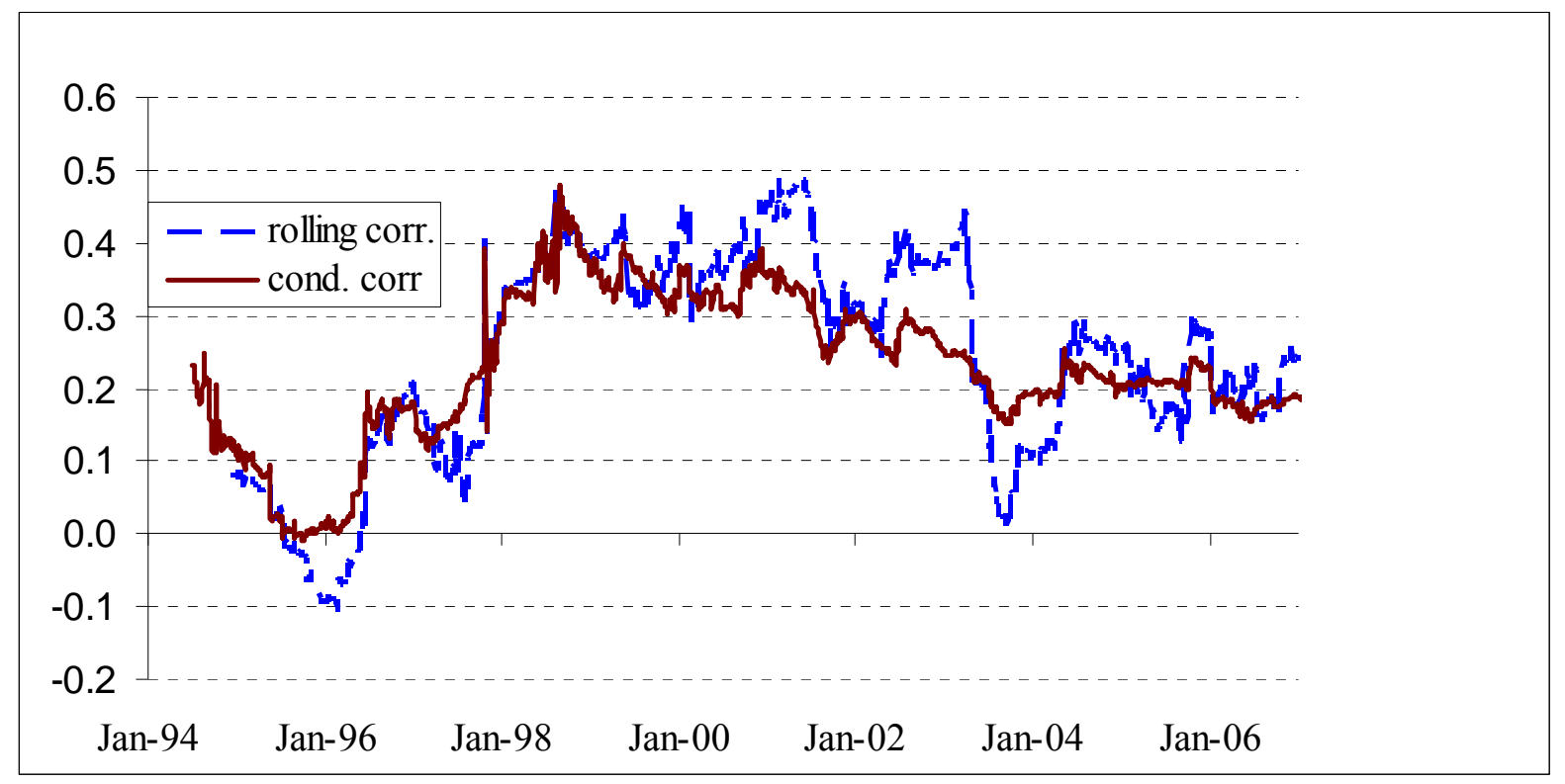

Figure 2. Six-month rolling window correlation and conditional correlation between Russian equity market indices and the JPM EMBI Russia index from 1994 to 2007. Conditional correlation is calculated on the basis of the estimates in Table 3.

It may also be noted from Figure 2 that the conditional and rolling window stock-bond return correlations exhibit a very similar pattern over time. However, as expected, the rolling window correlation estimates appear to be considerably more unpredictable than the conditional correlations produced by the DCC model. Moreover, the DCC estimates should account for the changes in volatility, and thus be free from the possible rising bias during the periods of economic meltdown.

\subsection{Dynamic Conditional Correlation estimates}

Acknowledging the reality that the constant correlation coefficient fails to reveal the dynamic market conditions in response to innovation, next the DCC GRCH $(1,1)$ model proposed by Engle (2002) was applied. Basically, the DCC-GARCH model estimates conditional volatilities and correlations in two steps. In the first step the mean equation of each asset in the sample, nested in a univariate GARCH model of its conditional variance, is estimated (see Figure 3), whereas the second step illustrates the development of the time varying correlation matrix (see Figure 2). The results in Table 2 confirm that the conditional correlations of bond and stock returns are highly dynamic and time varying. This is evident from Figure 3 as well, which presents the plots of conditional variances based on the estimation done in the first step of the DCC estimation procedure. 


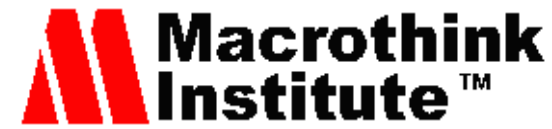

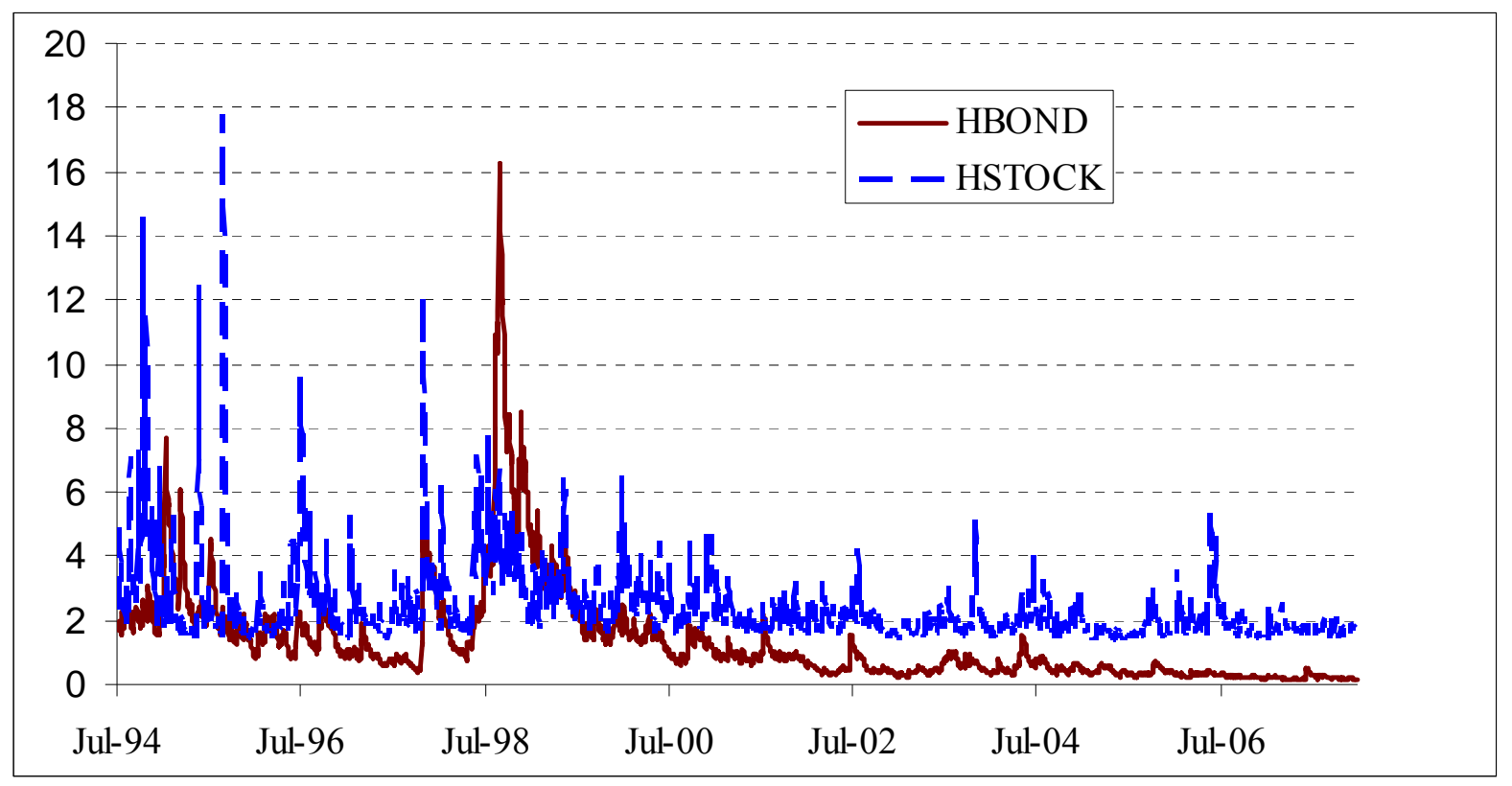

Figure 3. Conditional volatilities in Russian equity market indices and the JPM EMBI Russia index from 1994 to 2007.

The figure above shows that the conditional variances are not constant over time and especially volatile during the periods before and during the Russian financial crisis of 1998 . Moreover it seems that the volatilities of Russian stocks and bonds move together, which is consistent with prior research. For instance, Schwert (1989) found that volatily in the US stock and bond market tend to move together.

From Table 3, it is evident that the estimates of the mean equation and variance equation are statistically significant which is consistent with time varying volatility and justifies a clustering phenomenon in the evolution of volatility. Moreover, the sum of estimated coefficients $\left(\delta_{D C C S}+\delta_{D C C b}\right)$ in the variance equation is close to unity, implying that volatility exhibits a highly persistent behavior.

Table 3. Bond-stock bivariate DCC-GARCH $(1,1)$ model

\begin{tabular}{lllllll}
\hline & $\mu$ & $\omega$ & $\alpha$ & $\beta$ & $\delta_{D C C S}$ & $\delta_{D C C b}$ \\
\hline \multirow{2}{*}{ Stock } & $0.148^{*}$ & $0.016^{*}$ & $0.022^{*}$ & $0.977^{*}$ & & \\
& & & & & & \\
& $(0.032)$ & $(0.000)$ & $(0.001)$ & $(0.001)$ & $0.005^{*}$ & $0.993^{*}$ \\
Bond & $0.061^{*}$ & $0.026^{*}$ & $0.079^{*}$ & $0.920^{*}$ & & \\
& & & & & & \\
& $(0.006)$ & $(0.000)$ & $(0.005)$ & $(0.005)$ & $(0.001)$ & $(0.001)$ \\
\hline
\end{tabular}

Results are reported from a bivariate dynamic conditional correlation GARCH $(1,1)$ process; conducted by using daily returns on bond and stock market indices for Russia from July 1994 
to December2007. In the Table, $\mu$ represents the constant from the mean equation whereas $\omega$, $\alpha$ and $\beta$ are the parameters of bivariate GARCH processes. The parameters, $\delta_{D C C S}$ and $\delta_{D C C b}$, are DCC-GARCH estimates of stock and bond, respectively. Standard errors are in ( ).* indicates the significance at $5 \%$ level.

\section{Asymmetric Dynamic Conditional Correlation estimates}

The DCC model perfectly overcomes the heteroskedasticity problem since the residuals of the returns are standardized by the conditional standard deviation based on the GARCH $(1,1)$ process. However, it does not account for the asymmetries in conditional variances, covariances, and correlations. Hence, an asymmetric version of the Dynamic Conditional Correlation (ADCC) model proposed by Cappiello et al. (2006) was adopted to deal with the asymmetries in conditional variances, covariances, and correlations of the two assets. Table 4 presents the empirics.

Again the GARCH $(1,1)$ parameters are highly significant confirming the time varying variance-covariance process as well as strengthening the use of multivariate GARCH modeling for the Russian stock and bond market data. Parameter $\gamma$ measures the asymmetries in conditional variances, covariances, and correlations, and in this regard the results proved to be very interesting. Empirics show that the Russian bond market and stock market both exhibits positive asymmetries in conditional variances, covariances, and correlations.

Table 4. Bond-stock bivariate ADCC-GARCH $(1,1)$ model

\begin{tabular}{llllllll}
\hline & $\mu$ & $\omega$ & $\alpha$ & $\beta$ & $\gamma$ & $\delta_{D C C S}$ & $\delta_{D C C b}$ \\
\hline \multirow{2}{*}{ Stock } & $0.080^{*}$ & $-0.025^{*}$ & $0.022^{*}$ & $0.977^{*}$ & $0.001^{*}$ & & \\
& $(0.009)$ & $(0.000)$ & $(0.001)$ & $(0.001)$ & $(0.000)$ & $0.007^{*}$ & $0.982^{*}$ \\
& & & & & & & \\
Bond & $0.062^{*}$ & $0.008^{*}$ & $0.098^{*}$ & $0.901^{*}$ & $0.044^{* *}$ & & \\
& $(0.007)$ & $(0.000)$ & $(0.007)$ & $(0.007)$ & $(0.007)$ & $(0.002)$ & $(0.002)$ \\
\hline
\end{tabular}

Results are reported from a bivariate asymmetric dynamic conditional correlation GARCH (1, 1) model, conducted using daily returns on bond and stock market indices for Russia from July 1994 to December 2007. In the Table, $\mu$ represents the constant from the mean equation whereas $\omega, \alpha$ and $\beta$ are the parameters of bivariate GARCH processes. $\gamma$ account for asymmetric behaviour. The last parameters, $\delta_{D C C S}$ and $\delta_{D C C b}$, are DCC-GARCH estimates of stock and bond, respectively. Standard errors are in ( ). * $\left.{ }^{* *}\right)$ indicate the significance at 5\% $(10 \%)$ level.

Finally, the significance of DCC-GARCH estimates $\delta_{D C C S}$ and $\delta_{D C C b}$ once again allow us to conclude that conditional correlations of bond and stock returns are highly dynamic and time varying. 


\section{Summary and Conclusions}

In this study we address one of the most fundamental issues of traditional and modern portfolio management, i.e., the dynamics of stock-bond correlation and how it might perform in the future. Stock-bond correlation plays an important role in asset allocation, portfolio management and risk management. Despite its importance, this phenomenon has been severely ignored in the context of emerging markets, regardless of their high returns and favorable diversification opportunities. We chose the Russian stock and bond market as a test laboratory due to its rapid growth and attraction to both domestic and international investors.

The co-movements between the returns on the stock and bond markets of Russia were modeled by using multivariate conditional volatility models. The investigation started by applying Bollerslev's (1990) Constant Conditional Correlation model to test whether varying correlations are statistically significant. Then the DCC-GARCH $(1,1)$ model proposed by Engle (2002) was used to analyze the dynamics of conditional correlations between the two assets. Finally, to investigate the asymmetries in conditional variances, covariances, and correlations, an asymmetric version of the Dynamic Conditional Correlation (ADCC) model proposed by Cappiello et al. (2006) was adopted.

The empirical results do not support the assumption of constant conditional correlation and there was clear evidence of time varying correlations between the Russian stocks and bond market. Moreover, both asset markets exhibit positive asymmetries. We believe that our results offer a better understanding of the dynamics of the correlations between the stocks and bonds in an emerging market setting which is obviously very valuable for portfolio managers, international investors, risk analysts and financial researchers as well as for its policy implications.

\section{References}

Abid, F., Aoua, N., Mikhail, A.D. (2003). Linkages between, and contagion in, Asian stock and foreign exchange markets. Finance India 17, 1311-1343.

Alexander, G., Edwards, A., Ferri, M. (2000). What does NASDAQ's high-yield bond market reveal about bondholder-stockholder conflicts? Financial Management 29, 23-39.

Barsky, R. B. (1989). Why don't the prices of stocks and bonds move together? American Economic Review 79, 1132-1145.

Baur, D., Lucey, B.M. (2009). Flight and contagion - An empirical analysis of stock-bond $\begin{array}{lllll}\text { correlations. Journal of Financial stability } & \text { 5, }\end{array}$ http://dx.doi.org/10.1016/j.jfs.2008.08.001

Bollerslev, T. (1990). Modeling the coherence in short-run nominal exchange rates: A multivariate generalized ARCH model. Review of Economics and Statistics 72, 498-505.

Bollerslev T., Engle, R.F., Wooldridge, J.M. (1988). A capital asset pricing model with timevarying covariances. Journal of Political Economy 96, 116-131.

Bollerslev, T. (1986). Generalized Autoregressive Conditional Heteroskedasticity. Journal of 
Econometrics, 31, 307-27. http://dx.doi.org/10.1016/0304-4076(86)90063-1

Connolly, R., Stivers, C., Sun, L. (2005). Stock market uncertainty and the stock- bond return relation. Journal of Financial and Quantitative Analysis, 40, 161-194. http://dx.doi.org/10.1017/S0022109000001782

Campbell, J., Ammer, J. (1993). What moves the stock and bond markets? A variance decomposition for long-term asset returns. Journal of Finance, 48, 3-37.

Cappiello, L., Engle, R., Sheppard, K. (2006). Asymmetric dynamics in the correlations of global equity and bond returns. Journal of Financial Econometrics 4, 537-572. http://dx.doi.org/10.1093/jjfinec/nb1005

Chesnay, F., Jondeau, E. (2001). Does correlation between stock returns really increase during turbulent periods. Economic Notes by Banca Monte dei Paschi di Siena SpA.

Engle, R. (2002). Dynamic Conditional Correlation - A simple class of multivariate GARCH models. Journal of Business and Economic Statistics, 20, 339-350. http://dx.doi.org/10.1198/073500102288618487

Engle R.F., Kroner, K.F. (1995). Multivariate simultaneous generalized ARCH. Econometric Theory 11, 122-150. http://dx.doi.org/10.1017/S0266466600009063

Engle, R.F., Sheppard, K. (2001). Theoretical and Empirical Properties of Dynamic Conditional Correlation Multivariate GARCH, Working Paper, UCSD, San Diego.

Engle, R. F. (1982). Autoregressive conditional heteroskedasticity with estimates of the variance of United Kingdom inflation, Econometrica, 50, 987-1007.

Gulko, L. (2002). Decoupling. Journal of Portfolio Management, 28, 59-67. http://dx.doi.org/10.3905/jpm.2002.319843

Ilmanen, A. (2003). Stock-bond correlations. Journal of Fixed Income, 13, 55-66. http://dx.doi.org/10.3905/jfi.2003.319353

Jones, C., Wilson, J. (2004). The changing nature of stock and bond volatility. Financial Analysts Journal, 60, 100-113.

Kwan, S. H. (1996). Firm-Specific Information and the Correlation between Individual Stocks and Bonds. Journal of Financial Economics, 40, 63-80. http://dx.doi.org/10.1016/0304-405X(95)00836-4

Keim, D.B. Stambaugh, E.B. (1986). Predicting returns in the stock and bond markets. Journal of Financial Economics, $17, \quad 357-390$. http://dx.doi.org/10.1016/0304-405X(86)90070-X

Li, L. (2002). Macroeconomic Factors and the Correlation of Stock and Bond Returns. Unpublished working paper. Yale International Center for Finance.

Markowitz, H. (1952). Portfolio Selection. Journal of Finance 7, 77-91. 


\section{Macrothink}

Asian Journal of Finance \& Accounting ISSN 1946-052X 2011, Vol. 3, No. 1: E5

Markowitz, H. (1959). Portfolio Selection: Efficient Diversification of Investments. New York: Wiley (2nd Ed.) Cambridge, MA: Basil Blackwell, 1991.

Saleem, K., Vaihekoski, M. (2008). Pricing of global and local sources of risk in Russian stock market. Emerging Markets Review 40-56. http://dx.doi.org/10.1016/j.ememar.2007.08.002

Schwert, G. W. (1989). Why does stock market volatility change over time? Journal of Finance 44, 1115-53.

Shiller, R. (Beltratti, A., 1992). Stock prices and bond yields. Journal of Monetary Economics 30, 25-26. http://dx.doi.org/10.1016/0304-3932(92)90042-Z

Scruggs, J.T., Glabdanidis, P. (2003). Risk premia and the dynamic covariance between stock and bond return. Journal of Financial and Quantitative Analysis 38, 295-316. http://dx.doi.org/10.2307/4126752

Siegel, J.J. (1998). Stock for the long run: A guide to selecting markets for long- term growth. IRWIN Professional Publishing. 